\title{
A Study on the Relationship between the Independence of the Central Bank and China's Inflation
}

\author{
Yansong Zheng \\ Anhui University of Finance and Economics, Longzihu Campus, Bengbu, China \\ Email: zhengys1998@163.com
}

How to cite this paper: Zheng, Y. S. (2020). A Study on the Relationship between the Independence of the Central Bank and China's Inflation. Open Journal of Social Sciences, 8, 263-270. https://doi.org/10.4236/jss.2020.82021

Received: January 15, 2020

Accepted: February 25, 2020

Published: February 28, 2020

Copyright ( 2020 by author(s) and Scientific Research Publishing Inc. This work is licensed under the Creative Commons Attribution International License (CC BY 4.0).

http://creativecommons.org/licenses/by/4.0/

\section{(c) (i) Open Access}

\begin{abstract}
In recent years, there have been several serious inflation problems in China. Western theorists believe that there is a certain relationship between the independence of the central bank and inflation in China (Chen, 2019). In this paper, LS measure method is used to measure the independence of the central bank, and the inflation rate of 1994-2017 in China is calculated. Based on the collected data, the time series analysis of the independence of the central bank and the inflation in China is carried out. It holds that the independence of the central bank is negatively related to inflation, and aims to improve the independence of the central bank in China and lay the foundation for stabilizing the price level.
\end{abstract}

\section{Keywords}

Independence of Central Bank, Inflation Rate, Time Series Analysis, LS Measurement Method

\section{Introduction}

Over the past 40 years, China has experienced several periods of severe inflation and asset bubble pressure. China's CPI index has maintained a relatively high level of growth. The most important reason for inflation is the excessive expansion of the currency. In 1995, the growth rate of broad money was as high as $29 \%$. In recent years, although the growth rate of broad money has declined in general, it remains at a high level. The monetary policy of the central bank can help to stabilize prices and curb inflation. Walsh uses the principal-agent model to prove that the stronger the independence of the central bank, the more likely it is to take inflation as the policy goal. Therefore, it is particularly urgent to 
study the relationship between the independence of the central bank and inflation in China.

As a special financial institution, the central bank has become an indispensable part of modern financial and economic life. Because of its own functional characteristics, independence has become its important nature. The independence of the central bank refers to the degree of autonomy of decision-making and action when the central bank performs its duties. The independence of the central bank is mainly reflected in the government: first, the central bank and the government should maintain certain independence; second, the independence of the central bank for the government is relative. However, the central bank's monetary policy aiming at stabilizing prices is often disturbed by various factors, which will also affect the inflation of our country. Therefore, this paper studies the relationship between the independence of the central bank and China's inflation, in order to strengthen the independence of the central bank and ensure the stability of monetary policy and macroeconomic.

\section{Literature Review}

In the research field of the relationship between the independence of the central bank and inflation, it can be traced back to the academic disputes between the banking school and the inflation school in the $19^{\text {th }}$ century. At present, most scholars hold that there is a negative correlation between the independence of the central bank and inflation in China. Kong Zhangbin, et al. (2012), through the stage analysis of GDP and CPI and the establishment of OLS model, believe that there is a negative correlation between inflation and the independence of the central bank. Liu Qinsi (2013) uses var algorithm to make empirical analysis of the two, and believes that the stronger the independence of the central bank, the more conducive to achieving currency stability. In terms of the causal relationship between the independence of the central bank and inflation, Harold J. Brumm (2011) adopted the covariance structure model method on the basis of considering the endogeneity, and concluded that the causal relationship between the two is determined by each other. Cao Qiang (2014) collected the quarterly data from 1994 to 2012. Through the study of the relationship between the two, he believed that there was a cointegration relationship between the independence of the central bank and inflation, and that the pulse projection of the central bank was $\mathrm{U}$-shaped, and there was a lasting impact between the two. In the study of central bank independence and inflation control, Ren Biyun, et al. (2011), based on the macro-economic variables from 1978 to 2008, think that the independence of the central bank and inflation are not only negatively correlated, but also through interaction, we find that the moderate increase of the independence index of the central bank in the range of 14.28 to 20.65 will restrain inflation. Liu Tao (2017) obtained that CBI had significant negative correlation with CPI through linear regression of inflation rate and central bank independence from 1984 to 2013, and there was a long-term co integration relationship 
between them.

To sum up, scholars now analyze the relationship between the independence of the central bank and inflation from the perspective of macro data. Based on the LS measurement method, this paper measures the independence of the central bank in 1994-2017, and collects the M2 growth rate and GDP growth rate of China. Through the empirical analysis of the independence of the central bank and the inflation rate of China, the relationship between the two is studied through time series, aiming to better We should improve the independence of the central bank and curb inflation in China.

\section{Theoretical Basis}

\subsection{The Significance of the Independence of the Central Bank}

The independence of the central bank mainly refers to the autonomy of the central bank in making monetary policy. The original intention of the central bank determines that it should maintain its independence, because the central bank is based on the law of money itself the central bank exercises its functions on the basis of the law of money itself. If there is too much external intervention, it will not have a positive guiding role. If the central bank does not have independence, it means that it is impossible for the central bank to stabilize prices and money as the basic goal of monetary policy, and economic development will face more uncertainties. Therefore, the independence of the central bank in making monetary policy is the necessary condition to stabilize prices. The enhancement of the independence of the central bank will also restrain the inflation level of our country and eliminate the economic fluctuation caused by some political instability factors.

\subsection{A study of Inflation in China}

Inflation refers to the phenomenon that under the condition of paper money circulation, the money supply is greater than the money demand, which leads to the devaluation of money, and then causes the price to rise generally in a period of time. Inflation has the following effects on China: first, it makes the structure of income distribution more unequal; second, it brings many uncertainties to investors and consumers; third, it reduces the quality of life of residents. Therefore, this paper studies how to improve the independence of the central bank and stabilize the price level, which is of great significance to curb inflation.

\subsection{The Measurement Method of the Independence of the Central Bank}

At present, the methods to measure the independence of the central bank mainly include GMT method, CWN method, alesian method and eijfinger schaling method, while LS method is mainly used in the countries with economic transition. The main feature of LS law is to highlight the legislative focus on the policy authority and political independence of the central bank, and to consider the 
composition of the board of directors of the central bank as well as the position and decision-making of its members in detail. Therefore, based on China's national conditions, this paper uses LS method to measure and analyze the independence of China's central bank.

\section{Data Collection and Model Building}

\subsection{Data Collection}

\subsubsection{Central Bank Independence Index}

The data in this paper comes from EPS database. The independence of the central bank is measured by LS measurement method (Pang et al., 2019) and the specific national conditions of China. See Table 1 for LS measurement method and Table 2 for measurement results.

Table 1. LS measure method.

\begin{tabular}{|c|c|c|}
\hline Problem assignment & CBI-SIB & Weights \\
\hline $\begin{array}{l}\text { Whether the central bank can take price stability as the center of } \\
\text { economic target? }\end{array}$ & Yes $=0$, no $=1$ & $1 / 9$ \\
\hline $\begin{array}{l}\text { The central bank is able to control three monetary policy } \\
\text { instruments (discount rate, reserve ratio and open market } \\
\text { operation). }\end{array}$ & $\begin{array}{l}\text { The positive } \\
\text { answer for each } \\
\text { item is } 1 / 3 \text {, no }=0\end{array}$ & $1 / 9$ \\
\hline Is the government allowed to finance directly from the central bank? & Yes $=0$, no $=1$ & $1 / 9$ \\
\hline $\begin{array}{l}\text { Whether the central bank needs to accept the government's } \\
\text { instructions when implementing monetary policy? }\end{array}$ & Yes $=0$, no $=1$ & $1 / 9$ \\
\hline $\begin{array}{l}\text { Will the central bank be dissolved by the government due to } \\
\text { monetary policy conflict? }\end{array}$ & Yes $=0$, no $=1$ & $1 / 9$ \\
\hline $\begin{array}{l}\text { Whether the term of office of central bank officials exceeds the } \\
\text { election cycle? }\end{array}$ & Yes $=1$, no $=0$ & $1 / 9$ \\
\hline $\begin{array}{l}\text { Whether the term of office of the board of directors of the central } \\
\text { bank exceeds the election cycle? }\end{array}$ & Yes $=1$, no $=0$ & $1 / 9$ \\
\hline $\begin{array}{l}\text { Whether there are voting government representatives on the board } \\
\text { of directors of the central bank }\end{array}$ & Yes $=0$, no $=1$ & $1 / 9$ \\
\hline $\begin{array}{l}\text { Is there a government representative with veto power in the board } \\
\text { of directors of the central bank? }\end{array}$ & Yes $=0$, no $=1$ & $1 / 9$ \\
\hline
\end{tabular}

Table 2. CBI-SIB calculation results based on LS.

\begin{tabular}{ccccccc}
\hline Year & 1994 & 1995 & 1996 & 1997 & 1998 & 1999 \\
\hline Year & 2000 & 2001 & 2002 & 2003 & 2004 & 2005 \\
CBI-SIB & 6 & 6 & 6.17 & 4.33 & 5.43 & 6.3 \\
Year & 2006 & 2007 & 2008 & 2009 & 2010 & 2011 \\
CBI-SIB & 6.3 & 6.3 & 6.3 & 6.3 & 6.3 & 6.82 \\
Year & 2012 & 2013 & 2014 & 2015 & 2016 & 2017 \\
CBI-SIB & 6.82 & 6.82 & 6.82 & 6.82 & 6.82 & 6.82 \\
\hline
\end{tabular}




\subsubsection{Inflation Rate}

Based on Fisher's equation, inflation rate $=$ excess rate of money $=$ growth rate of money supply - real economic growth rate = growth rate of money supply (nominal economic growth rate - overall price index growth rate).This paper obtains the inflation rate $=$ the growth rate of broad money (M2) - the growth rate of GDP. See Table 3 for the specific results.

\subsection{Model Building}

Because the data collected in this paper are all time series with practical significance, we choose simple regression analysis to analyze the time series of central bank independence and inflation. In this paper, we use the time series method to set the inflation rate as the explanatory variable and CBI (the independence of the central bank) as the explanatory variable (Xue, 2019). The general model is

Table 3. Inflation rate in 1994-2017.

\begin{tabular}{|c|c|c|c|}
\hline year & M2 growth rate (\%) & GDP growth rate (\%) & Inflation rate (\%) \\
\hline 1994 & 31.5 & 13.08 & 18.42 \\
\hline 1995 & 29.46 & 10.92 & 18.54 \\
\hline 1996 & 25.27 & 10.01 & 15.26 \\
\hline 1997 & 20.73 & 9.3 & 11.43 \\
\hline 1998 & 14.9 & 7.83 & 7.07 \\
\hline 1999 & 14.67 & 7.62 & 7.05 \\
\hline 2000 & 12.32 & 8.43 & 3.89 \\
\hline 2001 & 15.04 & 8.3 & 6.74 \\
\hline 2002 & 13.14 & 9.08 & 4.06 \\
\hline 2003 & 19.24 & 10.03 & 9.21 \\
\hline 2004 & 14.89 & 10.09 & 4.8 \\
\hline 2005 & 16.74 & 11.31 & 5.43 \\
\hline 2006 & 22.12 & 12.68 & 9.44 \\
\hline 2007 & 16.74 & 14.16 & 2.58 \\
\hline 2008 & 17.78 & 9.63 & 8.15 \\
\hline 2009 & 28.42 & 9.21 & 19.21 \\
\hline 2010 & 18.95 & 10.45 & 8.5 \\
\hline 2011 & 17.32 & 9.3 & 8.02 \\
\hline 2012 & 14.39 & 7.65 & 6.74 \\
\hline 2013 & 13.59 & 7.67 & 5.92 \\
\hline 2014 & 11.01 & 7.4 & 3.61 \\
\hline 2015 & 13.34 & 6.9 & 6.44 \\
\hline 2016 & 11.33 & 6.7 & 4.63 \\
\hline 2017 & 8.11 & 6.9 & 1.21 \\
\hline
\end{tabular}


$\left\{\begin{array}{l}y_{t}=\beta_{0}+\beta_{1} x_{t 1}+\beta_{2} x_{t 2}+\cdots+\beta_{p} x_{t p}+\varepsilon_{t} \\ \left\{\varepsilon_{t}\right\} \sim W N\left(0, \sigma^{2}\right)\end{array} \cdot\left\{\varepsilon_{t}\right\} \sim W N\left(0, \sigma^{2}\right)\right.$ is white noise of the residual sequence.

\section{Empirical Analysis}

\subsection{Model Results}

In this paper, SPSS software is used to analyze the time series of the independence of the central bank and the inflation rate in China. The results of the scatter chart are shown in Figure 1. It can be seen that CBI and the inflation rate in China show an inverse correlation.

According to the regression analysis of time series, see Table 4 . The t-test of the model shows that the significance of the explained variables and the explained variables is very strong. The standardized regression coefficient of the model is -0.739 , that is to say, every unit increase in the independence index of the central bank corresponds to a decrease of 0.739 units in the inflation rate.

\subsection{Result Analysis}

By analyzing the time series data of CBI and inflation rate, we can see that the central bank and independence have not changed in the three stages of

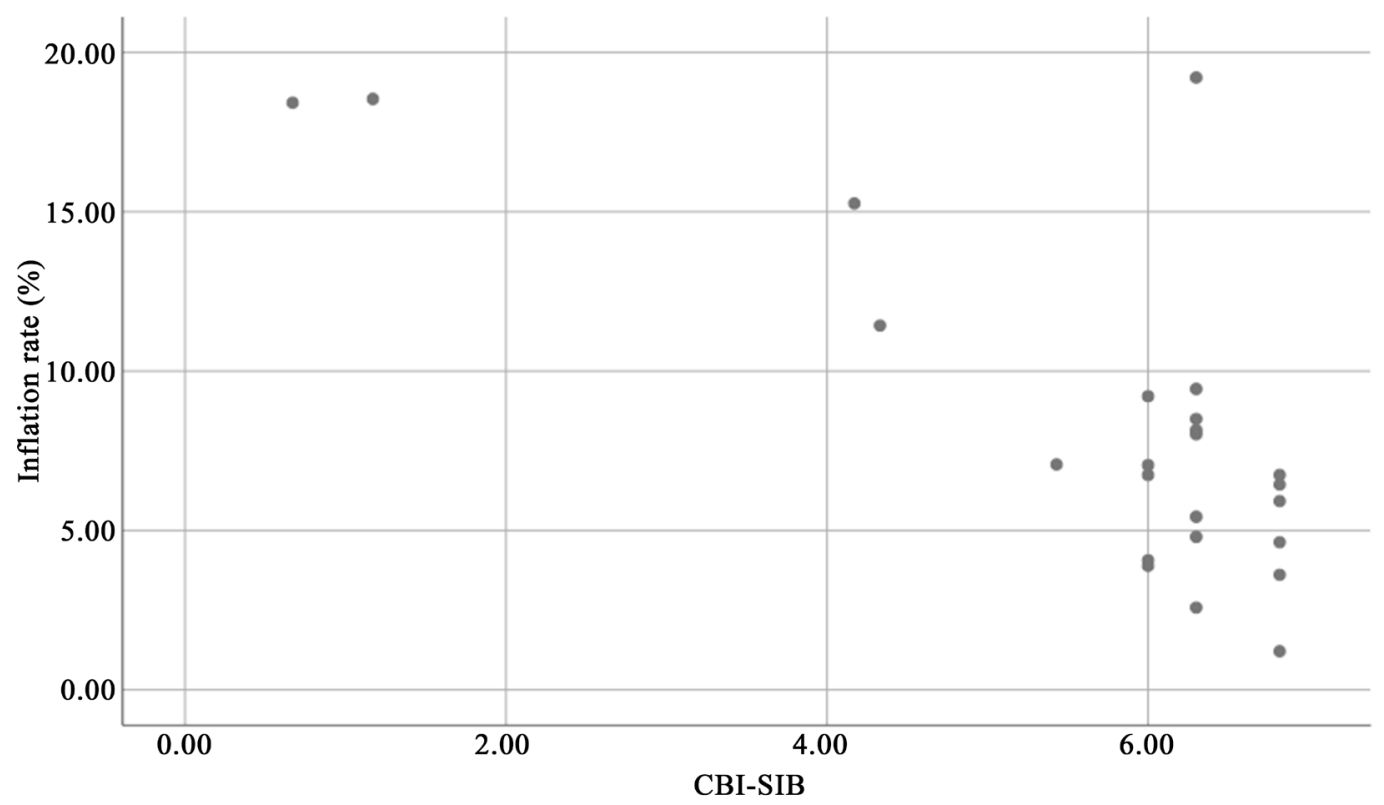

Figure 1. Scatter diagram of CBI and inflation rate.

Table 4. Regression analysis results of SPSS time series.

\begin{tabular}{cccccc}
\hline \multirow{2}{*}{ Model } & \multicolumn{2}{c}{ Non standardized coefficient } & \multicolumn{3}{c}{ standardized coefficient } \\
\cline { 2 - 6 } & B & Standard error & Beta & t & Saliency \\
\hline (constant) & 21.204 & 2.626 & & 8.074 & 0.000 \\
CBI-SIB & -2.28 & 0.443 & -0.739 & -5.148 & 0.000 \\
\hline
\end{tabular}


1994-2017, but the inflation rate of our country is changing every year, which may be because inflation is not only affected by the independence of the central bank, but also by economic cycle and other factors, especially in 1997 The Asian financial crisis and the global financial crisis in 2008. Generally speaking, China's inflation rate gradually decreases with the improvement of the independence of the central bank. Through the above empirical analysis, we can see that the gradual increase of the independence of the central bank can reduce the inflation rate of our country and help to maintain the price stability.

\section{Conclusion and Policy Recommendations}

At present, strengthening the independence of the central bank has gradually become a global trend. Based on the empirical results of time series analysis, we can see that there is a negative correlation between the independence of the central bank and the inflation rate. Therefore, in order to achieve macroeconomic stability, especially for developing countries, it is essential to improve the independence of the central bank. This paper puts forward policy suggestions from the following aspects:

First, the government should strengthen the decision-making power of the central bank's monetary policy. At present, due to the influence of many policies of our government and the mutual restriction of policy purposes, the monetary policy strength of the central bank is weakened, which limits the policy effectiveness of the central bank. Therefore, in order to strengthen the decision-making power of the central bank's monetary policy, based on the political nature of our country, the National People's Congress should establish an accountability mechanism for the central bank to formulate monetary policy, which is conducive to better supervision of the central bank and enhance the independence of the central bank.

Second, the supervision department should improve the transparency of the central bank's monetary policy. First of all, we should unify and standardize the relevant information disclosed by the central bank to realize the standardization of information disclosure; second, we should increase the disclosure of monetary policy decision-making, and the central bank should specify the basis for making monetary policy; finally, we should strengthen the evaluation mechanism of the masses, increase the credibility of the central bank in the hearts of the masses, and strengthen its credibility.

Third, the decision-making department should make clear the goal of monetary policy. China's monetary policy has dual characteristics, that is, it pays attention to both growth and inflation. For China, a developing country in the process of economic system reform, the importance of economic growth will be higher than that of price stability. However, blindly pursuing economic growth will lead to overheating, which will not be conducive to the economic development of the country. Therefore, the central bank should take price stability as the basic goal of monetary policy, which is conducive to better economic develop- 
ment.

Fourth, the central bank should improve the tenure mechanism of its officials. The central bank should adjust the structure of the staff, increase the proportion of professionals, reduce the proportion of government officials, and then reduce the government's intervention in the monetary policy decision of the central bank. At the same time, we should explain the appointment procedures of the central bank officials in more detail, increase the term of office of the central bank governor, reduce the frequency of governor replacement, and ensure the stability and consistency of the central bank's monetary policy.

\section{Conflicts of Interest}

The author declares no conflicts of interest regarding the publication of this paper.

\section{References}

Brumm, H. J. (2011). Inflation and Central Bank Independence: Two-Way Causality? Economics Letters, 111. https://doi.org/10.1016/j.econlet.2011.02.005

Cao, Q. (2014). Co Integration Analysis of Central Bank Independence and Inflation. Journal of North China Electric Power University (Social Science Edition), No. 2, 51-56.

Chen, J. (2019). Research on the Independence of the Central Bank: A Literature Review. Economic Research Guide, No. 4, 89-90 + 130.

Kong, Z. B., Zong, H. Q., \& Geng, J. (2012). The Relationship between the Independence of the Central Bank and Inflation. Shang, No. 5, 188.

Liu, Q. S. (2013). A Study on the Relationship between the Independence of the Central Bank and Inflation. Jinan: Shandong University.

Liu, T. (2017). A Study on the Relationship between the Independence of the Central Bank and Inflation. Chinese and foreign entrepreneurs, No. 32, 36-39.

Pang, H. F., Jing, K. Q., \& Qiu, H. Y. (2019). Research on the relationship between the Independence of the Central Bank and Inflation. Economic Research Guide, No. 20, $123-125+131$

Ren, B. Y., Huang, B., \& Yang, X. M. (2011). An Empirical Study on the Independence of the Central Bank of China and Inflation Control. Hebei Journal, 31, 146-149.

Xue, P. P. (2019). Research on the Relationship between the Independence of the RBA and Inflation. Economic Research Guide, No. 3, 84-86 + 99. 